\title{
Different levels of serum microRNAs in prostate cancer and benign prostatic hyperplasia: evaluation of potential diagnostic and prognostic role
}

This article was published in the following Dove Press journal:

OncoTargets and Therapy

13 December 2016

Number of times this article has been viewed

\author{
Giovanni Cochetti' \\ Giulia Poli² \\ Gabriella Guelfi ${ }^{3}$ \\ Andrea Bonil \\ Maria Giulia Egidi' \\ Ettore Mearini' \\ 'Department of Surgical and \\ Biomedical Sciences, Institution of \\ Urological, Andrological Surgery \\ and Minimally Invasive Techniques, \\ 2Department of Experimental \\ Medicine, Section of Terni, \\ ${ }^{3}$ Department of Veterinary Medicine, \\ University of Perugia, Perugia, Italy
}

Introduction: Diagnosis of prostate cancer $(\mathrm{PCa})$ is based on prostate biopsy that is performed when prostate specific antigen (PSA) is persistently altered over time and/or abnormal digital rectal examination is found. Serum PSA levels increase in both $\mathrm{PCa}$ and benign prostatic hyperplasia, leading to an increased number of unnecessary biopsies. There is an urgent need to unravel PCa-specific molecular signatures.

Patients and methods: This study aimed at characterizing a panel of circulating microRNAs (miRNAs) that could distinguish PCa from benign prostatic hyperplasia in a population of agematched patients with increased PSA levels. Both miRNAs targeting genes involved in PCa onset and miRNAs whose role in PCa has been highlighted in other studies were included. For this purpose, let-7c, let-7e, let-7i, miR-26a-5p, miR-26b-5p, miR-24-3p, miR-23b-3p, miR-27b-3p, miR-106a-5p, miR-20b-5p, miR-18b-5p, miR-19b-2-5p, miR-363-3p, miR-497, miR-195, miR-25-3p, miR-30c-5p, miR-622, miR-874-3p, miR-346 and miR-940 were assayed through real-time PCR in 64 patients with PCa and compared with 60 patients with benign prostatic hyperplasia. The ability of miRNAs to predict the stage of disease was also analyzed.

Results: Let-7c, let-7e, let-7i, miR-26a-5p, miR-26b-5p, miR-18b-5p and miR-25-3p were able to discriminate patients with $\mathrm{PCa}$ from those harboring benign prostatic hyperplasia, both presenting altered PSA levels ( $>3 \mathrm{ng} / \mathrm{mL}$ ). MiR-25-3p and miR-18b-5p showed the highest sensitivity and specificity to predict PCa, respectively. The combination of these two miRNAs improved the overall sensitivity. A correlation between pathological Gleason score and miRNA expression levels was reported; miR-363-3p, miR-26a-5p, miR-26b-5p, miR-106a-5p, miR-18b-5p, miR-25-3p and let-7i decreased in expression concomitantly with an increase in malignancy. Conclusion: This study confirms serum miRNAs to be reliable candidates for the development of minimally invasive biomarkers for the diagnosis and prognosis of $\mathrm{PCa}$, particularly in those cases where PSA acts as a flawed marker.

Keywords: miRNA, prostate cancer, serum, PSA, benign prostatic hyperplasia

\section{Introduction}

The main issue of management of prostate cancer $(\mathrm{PCa})$ is the poor accuracy of available diagnostic tools. In fact, a definitive diagnosis of PCa is based on prostate biopsy that, up to now, is performed when PSA is persistently altered over time and/ or abnormal digital rectal examination is found. In particular, PSA is an organ and not a tumor-specific marker, leading to an increased number of unnecessary biopsies. If we think that $\mathrm{PCa}$ is the most common nonskin cancer worldwide ${ }^{1,2}$ and that PSA is a widespread screening tool even if debated many times, we realize the relevance of additional and more accurate noninvasive biomarkers that could diminish the number
Correspondence: Maria Giulia Egidi Department of Surgical and Biomedical Sciences, Institution of Urological, Andrological Surgery and Minimally Invasive Techniques, University of Perugia, Loc. S. Andrea delle Fratte, 06156 Perugia, Italy

Tel +3933835 I 9999

Fax +390744205822

Email mariagiuliaegidi@gmail.com 
of unuseful biopsies. Another issue of PCa management is the lack of tools that could detect clinically insignificant tumors that would not be life-threatening. Treatment of indolent disease could expose the patients to possible complications without reducing their risk of dying from $\mathrm{PCa}{ }^{3}$ Albertsen et $\mathrm{al}^{4}$ highlighted that the risk of dying from a Gleason score (GS) of 8-10 PCa within 10 years is $\sim 12.1 \%$, whereas this probability is minimal for low-grade disease. There is an urgent need to unravel PCa-specific molecular signatures that could accurately distinguish indolent from aggressive tumors in early stage, thereby reducing both overdiagnosis and overtreatment. The ideal early diagnostic biomarker should detect the aggressive PCa when it is still in a curable stage and should minimize the discovery of indolent form.

MicroRNAs (miRNAs) are small noncoding RNAs that govern gene expression through the complementary binding to target mRNAs, leading to their degradation. ${ }^{5}$ The progressive confirmation of their key role in cancer, their stability in biological fluids and their resistance to various storage conditions $^{6-9}$ make miRNAs excellent candidates for the development of minimally invasive biomarkers for cancer diagnosis and prognosis. Unfortunately, a universally accepted procedure to deal with miRNAs does not exist, and data normalization is currently performed through the experimental assessment of candidate housekeeping genes. ${ }^{10}$ This study was aimed at characterizing a panel of circulating miRNAs that could distinguish $\mathrm{PCa}$ from benign prostatic hyperplasia (BPH) in a population of age-matched patients with increased PSA levels. Both miRNAs targeting genes involved in PCa onset (IGF1R, PTEN, TP53, RB1, E2F2 and EZH2) and miRNAs whose role in PCa has been highlighted in other studies were included. For this purpose, 23 miRNAs belonging to let-7 (let-7c, let-7e and let-7i) and miR-26 (miR-26a-5p and miR-26b-5p) families, miRNAs from clusters 17 (miR-24-3p, miR-23b-3p and miR27b-3p), 7 (miR-106a-5p, miR-20b-5p, miR-18b-5p, miR19b-2-5p and miR-363-3p), 80 (miR-497 and miR-195), 35 (miR-25-3p) and 42 (miR-30c-5p), miR-622, miR-874-3p, miR-346, and miR-940 were assayed through real-time PCR in serum from 64 patients with PCa before surgery and compared to 60 patients with BPH. Stratification of PCa patients on the basis of GS allowed us to evaluate the ability of miRNAs to predict the grade of malignancy.

\section{Patients and methods}

\section{Patient selection}

This study was approved by the ethics committee of the University of Perugia. All patients provided written informed consent. From November 2014 to June 2015, 147 Caucasian age-matched patients with altered PSA levels $(>3 \mathrm{ng} / \mathrm{mL})$ were prospectively enrolled and underwent prostate biopsy, of whom 68 patients were affected with $\mathrm{PCa}$ and 79 patients with negative needle biopsy underwent transurethral prostate resection, which confirmed the diagnosis of $\mathrm{BPH}$. The following exclusion criteria were used: age $>75$ years, urinary infections, bladder stones and catheterization. PCa group accounted for 64 patients undergoing robot-assisted radical prostatectomy, since four patients with metastatic disease were not included. For all patients, serum levels of selected miRNAs were evaluated before surgery. All patients underwent fasting blood withdrawal. Patients with PCa were stratified according to pathological GS (pGS) and to the European Association of Urology (EAU) risk groups for biochemical recurrence of localized and locally advanced $\mathrm{PCa}$. This last classification considers PCa patients with PSA $<10 \mathrm{ng} / \mathrm{mL}$ and GS $<7$ and cT1c or cT2a as low risk, PCa patients with PSA from 10 to $20 \mathrm{ng} / \mathrm{mL}$ or $\mathrm{GS}=7$ or $\mathrm{cT} 2 \mathrm{~b}$ as intermediate risk and PCa patients with PSA $>20 \mathrm{ng} / \mathrm{mL}$ or GS $>7$ or cT2c as high risk. The expression values of selected serum miRNAs were evaluated in PCa and BPH groups.

\section{Selection of candidate miRNAs}

To search for interesting candidates, in silico prediction of putative miRNAs targeting PCa-associated genes was performed. Since the deregulation of specific miRNAs impacts on its mRNA targets and triggers malfunctioning of cellular activities, such alterations in expression could be linked to each other. Our attention was focused on IGF1R, PTEN, NRAS, TP53, RB1, E2F2 and EZH2 because of their crucial importance in the development of PCa. For this purpose, TargetScan Release 6.2 (http://www.targetscan. org), ${ }^{11}$ MicroCosm Targets Version 5 (http://www.ebi.ac.uk/ enright-srv/microcosm),${ }^{12}$ and microrna.org ${ }^{13}$ prediction algorithms were used. The following 23 miRNAs were selected for further analyses: miRNAs belonging to let-7 (let-7c, let-7e and let-7i) and miR-26 (miR-26a-5p and miR-26b-5p) families, miRNAs from clusters 17 (miR-24-3p, miR-23b-3p and miR-27b-3p), 7 (miR-106a-5p, miR-20b-5p, miR-18b-5p, miR-19b-2-5p and miR-363-3p), 80 (miR-497 and miR-195), 35 (miR-25-3p) and 42 (miR-30c-5p), miR-622, miR-874-3p, miR-346 and miR-940.

\section{RNA isolation}

Blood was withdrawn into Vacuette ${ }^{\circledR}$ Z Serum Sep Clot Activator (Greiner Bio-One). After centrifugation $(2,000 \times g$, 10 minutes), serum was obtained and stored at $-80^{\circ} \mathrm{C}$ until use. 
RNA was isolated from $500 \mu \mathrm{L}$ of serum using Plasma/Serum Circulating and Exosomal RNA Purification Mini Kit (Slurry Format; Norgen Biotek Corp., Thorold, ON, Canada). Total RNA was stored at $-20^{\circ} \mathrm{C}$ until use. During RNA isolation, UniSp4 spike-in RNA (miRCURY LNATM Universal RT microRNA PCR, RNA Spike-in kit; Exiqon, Vedbaek, Denmark) was introduced as RNA isolation control.

\section{Reverse transcription and real-time PCR}

A total of $4 \mu \mathrm{L}$ of purified RNA (from a total volume of $100 \mu \mathrm{L}$ eluate) was reverse-transcribed using the miRCURY LNA ${ }^{\mathrm{TM}}$ Universal RT microRNA PCR, Polyadenylation and cDNA synthesis kit (Exiqon). A total of $0.5 \mu \mathrm{L}$ of UniSp6 RNA was spiked in the RT mix for the quality control of cDNA synthesis. The total reaction volume was $10 \mu \mathrm{L}$. Primers for mature sequences of selected miRNAs were purchased from Exiqon (microRNA LNA ${ }^{\mathrm{TM}}$ PCR primer set). No-template controls were included. All PCR assays (total reaction volume: $20 \mu \mathrm{L}$ ) were run on an iCycler $\mathrm{iQ}^{\mathrm{TM}}$ Real-Time PCR Detection System (Bio-Rad Laboratories, Hercules, CA, USA). SYBR Green master mix was used (miRCURY LNA ${ }^{\mathrm{TM}}$ Universal RT microRNA PCR SYBR ${ }^{\circledR}$ Green Master Mix; Exiqon). PCR amplification efficiencies were calculated for each individual miRNA using the following equation: $E=$ $\left(10^{-1 / s l o p e}-1\right) \times 100$. The efficiency threshold was calculated at $\pm 10 \%$ across a 10 -fold dilution series across five points. Candidate housekeeping genes were selected on the basis of literature data and manufacturer's recommendations. After stability assessment assays, data were normalized against the mean between miR-191-5p and miR-425-5p Ct values as follows: $-\Delta \mathrm{Ct}=-\left(\mathrm{Ct}_{\text {target }}-\mathrm{Ct}_{\text {miR-191-5p+miR-425-5p }}\right)$. Values are reported as the mean $\pm \mathrm{SD}$.

\section{Total PSA assay}

Total serum PSA measurements were performed through ADVIA Centaur automated system (Siemens Healthcare Diagnostics, Bayswater, VIC, Australia). The two-site sandwich immunoassay consists of a polyclonal goat anti-PSA antibody and a monoclonal mouse anti-PSA antibody.

\section{Statistical analysis}

Statistical analyses were performed using GraphPad Prism (GraphPad Software, San Diego, CA, USA) and XLSTAT (Microsoft Corporation, Redmond, WA, USA). KruskalWallis and Mann-Whitney tests were performed. The significance threshold was set at 0.05 . Logistic regression analysis was performed to test the association of selected genes with the outcome. Prediction models were based on miRNA expression values (expressed as $-\Delta \mathrm{Cts}$ ). Univariate logistic regression analysis was performed for each independent variable, and thereafter, multivariate logistic models were built. Specificity and sensitivity were combined in receiver operating characteristic (ROC) curve analysis and reported in areas under the curves (AUCs).

\section{Results}

\section{Patients' characteristics and expression of candidate miRNAs}

Patient's characteristics and clinicopathological data are listed in Table 1. All statistical comparisons are resumed in Table 2. MiR-195-5p, miR-20b-5p, miR-940, miR-19b-5p, miR-622 and miR-874-3p were undetectable in almost all subjects under analysis. All miRNAs showing significant alterations in expression were downregulated in PCa with respect to the BPH group. In particular, miRNAs belonging to let family (let-7i, let-7e and let-7c) significantly decreased in the PCa group with respect to BPH and the same was true for miR-26 family members (miR-26a-5p and miR-26b-5p). Regarding cluster 7, only miR-18b-5p (miR-17 family) significantly decreased in expression in the PCa group, while miR-106a-5p, miR-363-3p, miR-24-3p, miR-23b-3p and miR-27b-3p did not show significant modifications. All the

Table I Patients' characteristics and clinicopathological data of subjects involved in the study

\begin{tabular}{|c|c|c|}
\hline Characteristics & $\mathrm{PCa}(\mathrm{n}=64)$ & BPH $(n=79)$ \\
\hline Mean age (range), years & $63(53-66)$ & $59(53-65)$ \\
\hline Mean PSA (range), ng/mL & $5.50(3.20-9.3)$ & $4.85(2.59-8.6)$ \\
\hline \multicolumn{3}{|l|}{ Clinical stage, n (\%) } \\
\hline TIc & $40(62.5)$ & \\
\hline $\mathrm{T} 2 \mathrm{a}$ & $4(6.2)$ & \\
\hline $\mathrm{T} 2 \mathrm{~b}$ & $8(12.5)$ & \\
\hline $\mathrm{T} 2 \mathrm{c}$ & $12(18.8)$ & \\
\hline \multicolumn{3}{|l|}{ Pathological Gleason score } \\
\hline $6(3+3)$ & 35 & \\
\hline $7(3+4)$ & 16 & \\
\hline $7(4+3)$ & 9 & \\
\hline $8(4+4)$ & 4 & \\
\hline Lymph node involvement, n (\%) & $8(12.5)$ & \\
\hline \multicolumn{3}{|l|}{ Pathological stage, n (\%) } \\
\hline $\mathrm{T} 2 \mathrm{a}$ & $28(43.75)$ & \\
\hline $\mathrm{T} 2 \mathrm{~b}$ & $18(28.12)$ & \\
\hline $\mathrm{T} 2 \mathrm{c}$ & $16(25)$ & \\
\hline T3a & $2(3.13)$ & \\
\hline \multicolumn{3}{|c|}{$\begin{array}{l}\text { EAU risk groups for biochemical recurrence of localized and locally } \\
\text { advanced } \mathrm{PCa}\end{array}$} \\
\hline $\begin{array}{l}\text { advanced } \mathrm{PCa} \\
\text { Low risk }\end{array}$ & $\mathrm{N}=28$ & \\
\hline Intermediate risk & $N=18$ & \\
\hline High risk & $N=18$ & \\
\hline
\end{tabular}

Abbreviations: $\mathrm{BPH}$, benign prostatic hyperplasia; EAU, European Association of Urology; PCa, prostate cancer; PSA, prostate specific antigen. 
Table 2 Statistical analysis of selected miRNAs between PCa $(n=64)$ and BPH $(n=60)$ subjects

\begin{tabular}{|c|c|c|c|c|}
\hline Position ID & Family ID & ID & $P$-value & Trend (PCa vs BPH) \\
\hline Chrl2 & Let & Let-7i & 0.05 & Down \\
\hline Chrl9 & & Let-7e & 0.004 & Down \\
\hline Chr2I & & Let-7c & 0.05 & Down \\
\hline \multirow[t]{2}{*}{ Chr2 } & $\operatorname{miR}-26$ & $m i R-26 a-5 p$ & 0.04 & Down \\
\hline & & $m i R-26 b-5 p$ & 0.05 & Down \\
\hline \multirow[t]{3}{*}{ Cluster 17 (chr9) gene cluster 24-2 } & $\operatorname{miR}-24$ & $\operatorname{miR}-24-3 p$ & 0.95 & NS \\
\hline & $\operatorname{miR}-23$ & $\operatorname{miR}-23 b-3 p$ & 0.66 & NS \\
\hline & $\operatorname{miR}-27$ & miR-27b-3p & 0.77 & NS \\
\hline \multirow[t]{5}{*}{ Cluster 7 (chrX) gene cluster 363} & miR-17 & miR-106a-5p & 0.98 & NS \\
\hline & & $m i R-20 b-5 p$ & Undetectable & NS \\
\hline & & miR-18b-5p & 0.04 & Down \\
\hline & miR-19 & $m i R-19 b-5 p$ & Undetectable & NS \\
\hline & miR-363 & $\operatorname{miR}-363-3 p$ & 0.53 & NS \\
\hline \multirow[t]{2}{*}{ Cluster 80 (chrl7) } & miR-497 & $\mathrm{miR}-497-5 \mathrm{p}$ & 0.36 & NS \\
\hline & miR-I5 & miR-195 & Undetectable & NS \\
\hline Cluster 35 (chr7) & $\operatorname{miR}-25$ & $m i R-25-3 p$ & 0.05 & Down \\
\hline Cluster $42(\mathrm{chrl})$ & $\operatorname{miR}-30$ & $m i R-30 c-5 p$ & 0.47 & NS \\
\hline ChrlO & $\mathrm{miR}-346$ & $\mathrm{miR}-346$ & 0.59 & NS \\
\hline Chrl3 & miR-622 & miR-622 & Undetectable & NS \\
\hline Chr5 & miR-874 & $m i R-874-3 p$ & Undetectable & NS \\
\hline Cluster 25 (chrl6) & miR-940 & miR-940 & Undetectable & NS \\
\hline
\end{tabular}

Abbreviations: $\mathrm{BPH}$, benign prostatic hyperplasia; NS, not significant; miRNAs, microRNAs; PCa, prostate cancer; Chr, chromosome.

remaining miRNAs (miR-346, miR-497-5p, miR-25-3p and miR-30c-5p) did not show appreciable alterations in expression. $-\Delta \mathrm{Ct}$ values of miRNAs significantly altered in this analysis are reported in Figure 1.

\section{Discriminative power of a panel of miRNAs for PCa}

Logistic regression analysis was performed to estimate the ability of selected miRNA to distinguish patients harboring

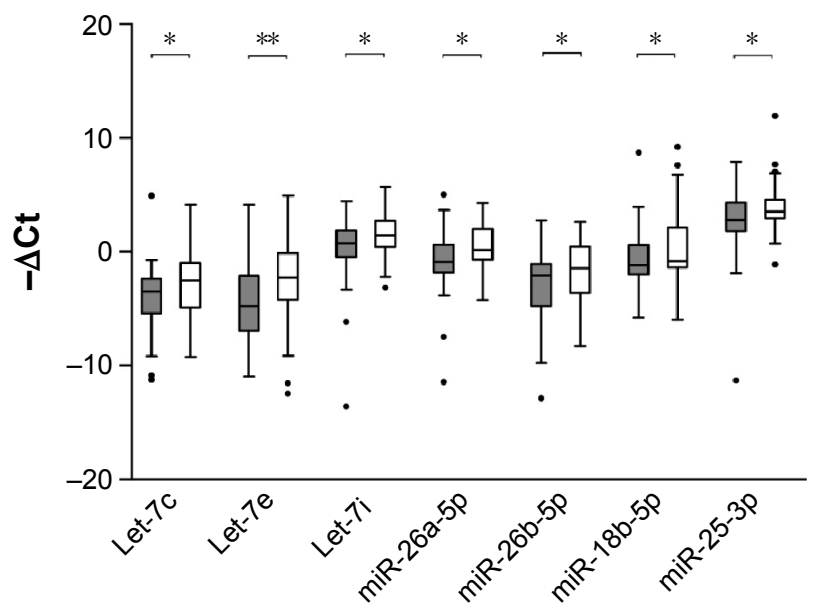

Figure I Expression levels (expressed as $-\Delta \mathrm{C} t$ ) of miRNAs significantly altered in PCa (gray) compared to BPH (white) subjects.

Note: Black lines and whiskers indicate median values and 10-90 percentile range, respectively. $* P<0.05 ; * * P<0.0$ I.

Abbreviations: $\mathrm{BPH}$, benign prostatic hyperplasia; miRNAs, microRNAs; $\mathrm{PCa}$, prostate cancer.
PCa from BPH group. First, univariate logistic regression analysis was performed; miRNAs with a significant difference in expression between groups were included. Results are reported in Table 3 and Figure 2. As can be seen in Table 3, let-7e, miR-26a-5p and miR-25-3p had acceptable 95\% CIs of ORs. MiR-25-3p showed the highest sensitivity (38.46\%), while miR-18b-5p displayed the highest specificity $(93.75 \%)$. Multivariate logistic regression analysis was performed combining together the most predictive miRNAs. Positively correlated miRNAs were not included in the same model. No model exceeded $93.75 \%$ specificity reached by miR-18b-3p alone. In the univariate analysis, miR-25-3p reached the highest sensitivity $(38.49 \%)$, while in the multivariate model, the combination of miR-18b-3p and miR-25-3p ameliorated the sensitivity of $+5.95 \%$. Figure 2 shows AUCs from univariate logistic regression analysis of the miRNAs under analysis. For miR-18b-5p and miR-25-3p, AUC of multivariate model is also included (solid line).

\section{Predictive power of miRNAs for PCa grading}

To evaluate the ability of selected miRNAs to predict the grade of malignancy, PCa patients were stratified according to pGS and risk of recurrence and progression. Results are shown in Figures 3 and 4. Overall, all miRNAs decreased in expression concomitantly with an increase in malignancy. 
Table 3 Logistic regression analysis of miRNAs with associated AUCs

\begin{tabular}{llllll}
\hline ID & OR & 95\% CI & AUC & \% SP & \% SN \\
\hline Let-7c & 0.861 & $0.731-1.015$ & 0.619 & 79.17 & 27.78 \\
Let-7e & 0.839 & $0.730-0.964$ & 0.693 & 85.71 & 29.03 \\
Let-7i & 0.811 & $0.654-1.005$ & 0.610 & 83.67 & 26.32 \\
miR-26a-5p & 0.825 & $0.682-0.997$ & 0.628 & 82.00 & 29.73 \\
miR-26b-5p & 0.867 & $0.747-1.007$ & 0.597 & 78.72 & 27.03 \\
miR-18b-5p & 0.867 & $0.738-1.019$ & 0.627 & 93.75 & 24.32 \\
miR-25-3p & 0.793 & $0.631-0.995$ & 0.629 & 88.00 & 38.46 \\
miR-18b-5p+ & 0.921 & $0.77 I-1.099$ & 0.667 & 89.58 & 44.44 \\
miR-25-3p & 0.809 & $0.629-1.040$ & & & \\
\hline
\end{tabular}

Abbreviations: $A \cup C s$, areas under the curves; $\mathrm{Cl}$, confidence interval; miRNAs, microRNAs; OR, odd ratio; SP, specificity; SN, sensitivity.

When patients were stratified according to pGS (Figure 3), miR-363-3p significantly decreased among pGS6, pGS7 and pGS8 patients, while miR-26b-5p, miR-106a-5p and let-7i were able to distinguish both pGS6 and pGS7 from pGS8, but not pGS6 from pGS7. On the contrary, miR-18b-5p and miR-25-3p significantly decreased in pGS7 when compared to $\mathrm{pGS} 6$ patients. When patients were stratified according to the risk of recurrence and progression (Figure 4), miR-363-3p significantly decreased only in high-risk patients versus lowrisk patients, and the same was true for miR-106a-5p and let-7i. MiR-26a-5p and miR-26b-5p could distinguish lowrisk patients from both intermediate- and high-risk patients, whereas miR-18b-5p and miR-25-3p were able to discriminate low-risk patients from intermediate-risk patients.

\section{Discussion}

$\mathrm{PCa}$ is the most frequently diagnosed cancer in men, and it represents the second cause of cancer-related death in developed countries; thus, the early diagnosis is of crucial importance to allow successful treatment. ${ }^{1,2}$ Currently, serum PSA is the best biomarker developed for the diagnosis of $\mathrm{PCa}$, but an increase in serum PSA levels due to BPH or inflammatory processes impairs its specificity. ${ }^{14}$ Moreover, its levels poorly correlate with tumor aggressiveness and, for this reason, PSA is a poor predictor of disease outcome. In addition to this, the misinterpretation of the results of prostate biopsy that may occur because of sampling errors in the presence of multifocal PCa should be considered. All these issues make the discovery of new biomarkers mandatory for the diagnosis and prognosis of $\mathrm{PCa} .{ }^{15} \mathrm{MiRNAs}$ are small noncoding RNAs exerting a modulatory function on gene expression binding to complementary sequences of mRNAs and leading to their degradation. ${ }^{5}$ The excellent stability of miRNAs in biological fluids ${ }^{7}$ and the mounting evidence of their crucial role in almost all biological processes, including cancer, ${ }^{6}$ make them good candidates for the development of minimally invasive biomarkers for cancer diagnosis and prognosis. This study aimed at characterizing the behavior of 23 serum miRNAs known to be involved in the development of PCa in a population of age-matched patients with altered PSA levels (>3 ng/mL) who received a needle biopsy for histological diagnosis of PCa. We sought to identify a panel of miRNAs with a predictive power for $\mathrm{PCa}$ : let-7c, let-7e, let-7i, miR-26a-5p, miR-26b-5p, miR-18b-5p and miR-25-3p significantly decreased in expression in $\mathrm{PCa}$ patients compared to $\mathrm{BPH}$ patients. Moreover, the ability of these miRNAs to predict PCa was assessed by means of logistic regression analysis. Let-7e, miR-26a-5p and miR-25-3p showed acceptable 95\% CIs of ORs; miR-25-3p showed the highest sensitivity $(38.46 \%)$, while miR-18b-5p displayed the highest specificity $(93.75 \%)$. In the multivariate model, the combination of miR-18b-5p and miR-25-3p was able to predict PCa with $89.58 \%$ specificity and $44.44 \%$ sensitivity ( $+6 \%$ compared to miR-25-3p alone). Current methodologies for isolating miRNAs from biological fluids are not standardized, and
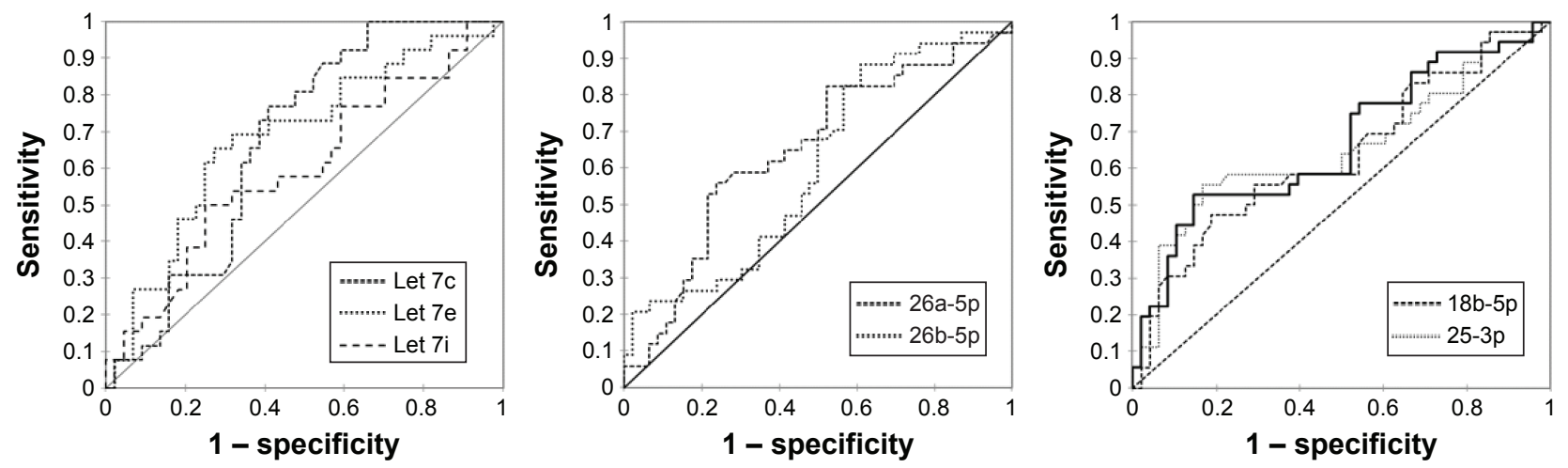

Figure 2 AUCs from univariate logistic regression analysis of the miRNAs under investigation. Note: For miR-I8b-5p and miR-25-3p, AUC of multivariate model is also included (solid line). Abbreviations: AUCs, areas under the curves; miRNAs, microRNAs. 


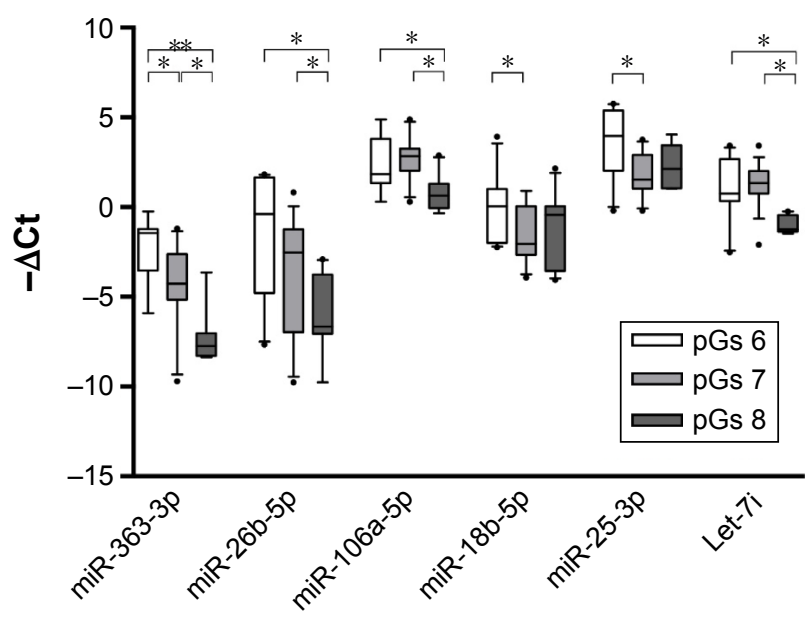

Figure 3 Expression levels (expressed as $-\Delta \mathrm{Ct}$ ) of miRNAs in PCa patients stratified according to $\mathrm{PGS}$.

Note: Black lines and whiskers indicate median values and 10-90 percentile range, respectively. $* P<0.05 ; * * P<0.01$.

Abbreviations: miRNAs, microRNAs; PCa, prostate cancer; pGS, pathological Gleason score.

thus results vary deeply from one laboratory to another. This leads to contrasting findings that are often reported for many miRNAs, among which those analyzed in this study. However, literature data regarding let family are quite concordant: their deletion has been documented for many human cancers ${ }^{16}$ and our results confirmed this downregulation. Regarding $\mathrm{PCa}$, this decrease in expression has been linked to cancer aggressiveness $^{17-20}$ and finds its rationale in the role of this family in carcinogenesis. Several let genes were reported to negatively regulate NRAS, ${ }^{21} \mathrm{c}-\mathrm{Myc},{ }^{22,23}$ and CCND2.${ }^{19}$ The c-Myc protein negatively regulates let-7 through the

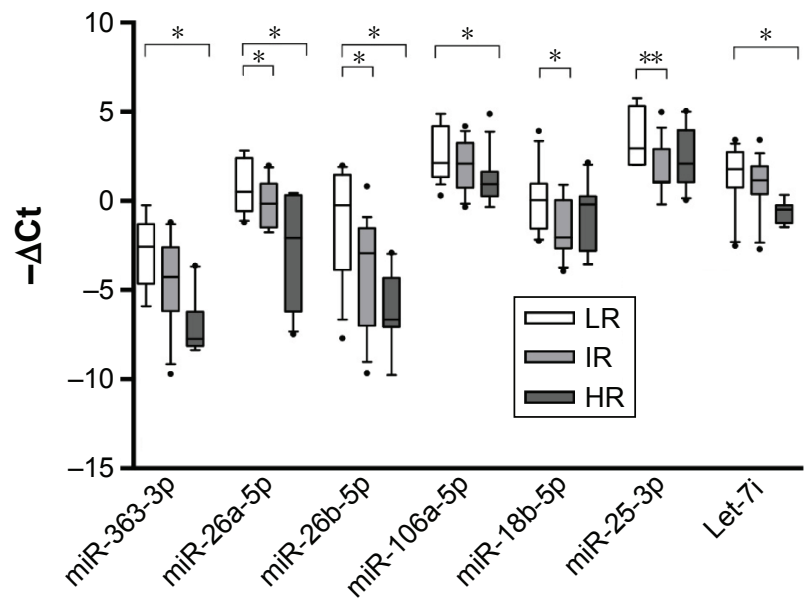

Figure 4 Expression levels (expressed as $-\Delta \mathrm{Ct}$ ) of miRNAs in PCa patients stratified according to risk of recurrence and progression.

Note: Black lines and whiskers indicate median values and 10-90 percentile range, respectively. $* P<0.05$; $* * P<0.0$ I.

Abbreviations: $H R$, high risk; IR, intermediate risk; LR, low risk; miRNAs, microRNAs; PCa, prostate cancer. stimulation of Lin2 $28^{24}$ and induces the expression of $\mathrm{AR}^{25}$ which in turn is able to trigger let-7 expression..$^{26} \mathrm{In} \mathrm{PCa}$, AR favors tumor survival and its downregulation impairs tumor growth. ${ }^{27}$ At the tissue level, let-7 is downregulated in localized PCa compared to benign peripheral region. ${ }^{28,29}$ Accordingly, let-7 overexpression is able to suppress $\mathrm{PCa}$ growth both in vitro and in vivo, suggesting that the reconstitution of let-7 expression provides benefits in cancer regression by decreasing survival and proliferation of tumor cells. In particular, this suppressive mechanism has been reported in PCa for let-7c, which influences the expression of AR through a Myc-dependent mechanism. ${ }^{18}$ The downregulation of let-7c has been widely established in PCa tissues compared to $\mathrm{BPH}$ counterparts. ${ }^{30-32}$ In plasma samples, let- $7 \mathrm{c}$ levels may distinguish $\mathrm{PCa}$ patients from $\mathrm{BPH}$ patients. ${ }^{33} \mathrm{~A}$ decrease in plasma levels of let-7c in PCa samples versus BPH samples was also reported in a recent study by Kachakova et al. ${ }^{34}$ The researchers performed an ROC curve analysis to evaluate the ability of let-7c in discriminating PCa patients from BPH patients: AUC $0.757(P=0.069)$, sensitivity $75 \%$ and specificity $61 \%$. These results are quite in accordance with our findings, where let-7c reached an AUC of 0.619 and a specificity of $79.17 \%$; in contrast, sensitivity found in this study was modest (27.78\%). Similar to let-7c, miR-30c has also been highlighted as a potential candidate with diagnostic power for PCa. ${ }^{33}$ Moreover, tissue levels of miR-30c varied according to pGS and EAU risk groups for biochemical recurrence of localized and locally advanced PCa. ${ }^{35}$ Despite these findings, no significant modifications in serum miR-30c levels were reported in this study.

Among all miRNAs analyzed in this study, miR-25-3p turned out to be the most sensitive predictor for $\mathrm{PCa}$, as shown in logistic regression analysis, with a sensitivity of $38.46 \%$. miR-25-3p, as part of the miR-106b-25 cluster, was reported to be upregulated in primary tumors and distant metastasis of $\mathrm{PCa}^{36-38}$ Moreover, many of its putative target genes are thought to take part in the promotion of PCa-invasive phenotype..$^{39,40}$ Despite its upregulation being documented in several miRNA profiling studies for $\mathrm{PCa},{ }^{37,39}$ a recent study demonstrated the shutdown in the expression of miR-25-3p in stem-like PCa cells, which was reactivated upon cell differentiation into luminal epithelial subtypes. ${ }^{41}$ These findings suggest a tumor-suppressive role for miR-25 in aggressive PCa cells. This inconsistency with previous literature data is justified by the heterogeneity of tumor tissue on which miRNA expression profiling studies were performed. The tumor-suppressive properties of miR-26 family have been widely reported for many cancers, such 
action being exerted via targeting of several oncogenes. For miR-26a, targeting of HMGA1 has been documented for bladder cancer, ${ }^{42}$ and targeting of HMGA2 for gallbladder cancer, ${ }^{43}$ targeting of FGF9 for gastric cancer, ${ }^{44}$ targeting of CKS2 for papillary thyroid carcinoma, ${ }^{45}$ targeting of NRAS and E2F2 for gastric cancer, ${ }^{46}$ and targeting of Wnt5a for PCa have been documented, ${ }^{47}$ while for miR-26b, targeting of COX-2 for lung cancer, ${ }^{48}$ EphA2 for glioma, ${ }^{49}$ USP9X for hepatocellular carcinoma, ${ }^{50} \mathrm{MIEN} 1$ for non-small-cell lung cancer, ${ }^{51}$ and ULK2 for $\mathrm{PCa}^{52}$ have been documented. In PCa, both miR-26a and miR-26b target La-related protein $1 .{ }^{53}$ At the tissue level, miR-26a ${ }^{30,54,55}$ and miR-26b are significantly downregulated in malignant tissue samples from prostatectomy specimens compared to matched nonmalignant counterparts. ${ }^{56}$ Nonetheless, increased levels in PCa tissues were also reported. ${ }^{37,39,57}$ Both miR-26a and miR-26b have been identified as regulators of EZH2: ${ }^{54,58}$ for miR-26a, this was also described in $\mathrm{PCa}{ }^{58,59}$ In various PCa cell lines, the overexpression of miR-26a and miR-26b represses both EZH2 mRNA and protein causing a reduction in cellular proliferation. ${ }^{55,58,60}$ Some researchers showed that the expression of miR-26a progressively decreased with increasing GS. ${ }^{61}$ This is in accordance with our findings, where a significant decrease in serum miR-26a and miR-26b with increasing disease severity has been reported.

MiR-23b/27b/24 cluster exerts tumor suppressor functions, and it is documented to decrease in expression in $\mathrm{PCa}$ tissues and cells. ${ }^{62}$ Although opposite findings have been documented for other malignancies such as breast cancer, ${ }^{63}$ the downregulation of miR-23b and miR-27b in metastatic castration-resistant $\mathrm{PCa}^{64}$ and the ability of these miRNAs in impairing metastatization processes ${ }^{65}$ have been reported. In this study, none of these miRNAs were significantly altered in serum from $\mathrm{PCa}$ patients compared to $\mathrm{BPH}$ patients. However, it is important to remember that the $\mathrm{PCa}$ group analyzed in this study included only patients with organconfined disease and not patients with metastatic PCa. Similarly, significant alterations were not found in serum levels of miR-497 between PCa and BPH samples, despite its role as tumor suppressor and its downregulation in $\mathrm{PCa}$ reported at the tissue level. ${ }^{66}$

The prognostic value of miRNAs analyzed in this work was also assessed; specifically, all miRNAs decreased in expression concomitantly with an increase in malignancy. The results highlight a significant correlation between $\mathrm{pGS}$ and miRNA expression levels: miR-363-3p decreased significantly among pGS6, pGS7 and pGS8 PCa, while miR26b-5p, miR-106a-5p and let-7i were able to distinguish both
pGS6 and pGS7 from pGS8; on the contrary, miR-18b-5p and miR-25-3p significantly decreased in pGS7 when compared to pGS6. When we stratified on the basis of risk of recurrence and progression, some miRNA signatures (miR-26a-5p and miR-26b-5p) could distinguish low-risk patients, who could be treated less aggressively, from both intermediate-risk and high-risk patients, who are worthy of more aggressive therapy, and also miR-18b-5p and miR-25-3p were able to discriminate low-risk patients from intermediate-risk patients. Furthermore, miR-363-3p, miR-106a-5p and let-7i may be potential markers of high-risk disease because they significantly decreased only in high-risk patients. A largescale clinical trial would be necessary to confirm the potential role of serum miRNAs as predictor of clinical outcome and cancer behavior of $\mathrm{PCa}$ patients.

\section{Conclusion}

This study demonstrated that let-7c, let-7e, let-7i, miR-26a-5p, miR-26b-5p, miR-18b-5p and miR-25-3p are able to discriminate patients with $\mathrm{PCa}$ from those harboring $\mathrm{BPH}$, both presenting altered PSA levels ( $>3 \mathrm{ng} / \mathrm{mL})$. MiR-25-3p and miR-18b-5p showed the highest sensitivity and specificity to predict $\mathrm{PCa}$, respectively. The combination of these two miRNAs improved the overall sensitivity. Furthermore, a significant correlation between pGS and miRNA expression levels was reported; miR-363-3p, miR-26a-5p, miR-26b-5p, miR-106a-5p, miR-18b-5p, miR-25-3p and let-7i decreased in expression concomitantly with an increase in malignancy. This study confirms serum miRNAs to be reliable candidates for the development of minimally invasive biomarkers for the diagnosis and prognosis of PCa, particularly in those cases where PSA acts as a flawed marker.

\section{Acknowledgment}

This study was supported by Fondazione Cassa Risparmio Perugia.

\section{Disclosure}

The authors report no conflicts of interest in this work.

\section{References}

1. Ferlay J, Steliarova-Foucher E, Lortet-Tieulent J, et al. Cancer incidence and mortality patterns in Europe: estimates for 40 countries in 2012. Eur J Cancer. 2013;49(6):1374-1403.

2. Siegel RL, Miller KD, Jemal A. Cancer statistics. CA Cancer J Clin. 2015;65(1):5-29.

3. Welch HG, Albertsen PC. Prostate cancer diagnosis and treatment after the introduction of prostate-specific antigen screening: 1986-2005. J Natl Cancer Inst. 2009;101(19):1325-1329.

4. Albertsen PC, Hanley JA, Fine J. 20-year outcomes following conservative management of clinically localized prostate cancer. $\mathrm{J} \mathrm{Am} \mathrm{Med} \mathrm{Assoc.}$ 2005;293(17):2095-2101. 
5. Bartel DP. MicroRNAs: genomics, biogenesis, mechanism, and function. Cell. 2004;116(2):281-297.

6. Schwarzenbach H, Nishida N, Calin GA, et al. Clinical relevance of circulating cell-free microRNAs in cancer. Nat Rev Clin Oncol. 2014; 11(3):145-156.

7. Mitchell PS, Parkin RK, Kroh EM, et al. Circulating microRNAs as stable blood-based markers for cancer detection. Proc Natl Acad Sci U S A. 2008;105(30):10513-10518.

8. Chen X, Ba Y, Ma L, et al. Characterization of microRNAs in serum: a novel class of biomarkers for diagnosis of cancer and other disease. Cell Res. 2008;18:997-1006.

9. Egidi MG, Cochetti G, Serva MR, et al. Circulating microRNAs and kallikreins before and after radical prostatectomy: are they really prostate cancer markers? Biomed Res Int. 2013;2013:241780.

10. Egidi MG, Cochetti G, Guelfi G, et al. Stability assessment of candidate reference genes in urine sediment of prostate cancer patients for miRNA applications. Dis Markers. 2015;2015:973597.

11. Lewis BP, Burge CB, Bartel DP. Conserved seed pairing, often flanked by adenosines, indicates that thousands of human genes are microRNA targets. Cell. 2005;120(1):15-20.

12. Enright AJ, John B, Gaul U, Tuschl T, Sander C, Marks DS. MicroRNA targets in Drosophila. Genome Biol. 2003;5(1):R1.

13. Betel D, Koppal A, Agius P, Sander C, Leslie C. Comprehensive modeling of microRNA targets predicts functional non-conserved and non-canonical sites. Genome Biol. 2010;11(8):R90.

14. Mazzucchelli R, Colanzi P, Pomante R, et al. Prostate tissue and serum markers. Adv Clin Pathol. 2000;4:111-120.

15. Saini S. PSA and beyond: alternative prostate cancer biomarkers. Cell Oncol (Dordr). 2016;39(2):97-106.

16. Calin GA, Sevignani C, Dumitru CD, et al. Human microRNA genes are frequently located at fragile sites and genomic regions involved in cancers. Proc Natl Acad Sci U S A. 2004;101(9):2999-3004.

17. Ramberg H, Alshbib A, Berge V, Svindland A, Taskén KA. Regulation of PBX3 expression by androgen and Let-7d in prostate cancer. Mol Cancer. 2011;10:article 50.

18. Nadiminty N, Tummala R, Lou W, et al. MicroRNA let-7c is downregulated in prostate cancer and suppresses prostate cancer growth. PLoS One. 2012;7(3): 32832.

19. Dong Q, Meng P, Wang T, et al. MicroRNA let-7a inhibits proliferation of human prostate cancer cells in vitro and in vivo by targeting E2F2 and CCND2. PLoS One. 2010;5(4):e10147.

20. Boyerinas B, Park SM, Hau A, Murmann AE, Peter ME. The role of let-7 in cell differentiation and cancer. Endocr Relat Cancer. 2010;17(1): F19-F36.

21. Johnson SM, Grosshans H, Shingara J, et al. RAS is regulated by the let-7 microRNA family. Cell. 2005;120(5):635-647.

22. Kim HH, Kuwano Y, Srikantan S, Lee EK, Martindale JL, Gorospe M. HuR recruits let-7/RISC to repress c-Myc expression. Genes Dev. 2009; 23(15): 1743-1748.

23. Sampson VB, Rong NH, Han J, et al. MicroRNA let-7a down-regulates MYC and reverts MYC-induced growth in Burkitt lymphoma cells. Cancer Res. 2007;67(20):9762-9770.

24. Piskounova E, Polytarchou C, Thornton JE, et al. Lin28A and Lin28B inhibit let-7 microRNA biogenesis by distinct mechanisms. Cell. 2011; 147(5):1066-1079.

25. Nadiminty N, Tummala R, Lou W, et al. MicroRNA let-7c suppresses androgen receptor expression and activity via regulation of Myc expression in prostate cancer cells. $J$ Biol Chem. 2012;287(2):1527-1537.

26. Lyu S, Yu Q, Ying G, et al. Androgen receptor decreases CMYC and KRAS expression by upregulating let-7a expression in ER-, PR-, AR+ breast cancer. Int J Oncol. 2014;44(1):229-237.

27. Andersen RJ, Mawji NR, Wang J, et al. Regression of castrate-recurrent prostate cancer by a small-molecule inhibitor of the amino-terminus domain of the androgen receptor. Cancer Cell. 2010;17(6):535-546.

28. Ozen M, Creighton CJ, Ozdemir M, Ittmann M. Widespread deregulation of microRNA expression in human prostate cancer. Oncogene. 2007;27(12):1788-1793.
29. Jiang J, Lee EJ, Gusev Y, Schmittgen TD. Real-time expression profiling of microRNA precursors in human cancer cell lines. Nucleic Acids Res. 2005;33(17):5394-5403.

30. Porkka KP, Pfeiffer MJ, Waltering KK, Vessella RL, Tammela TL, Visakorpi T. MicroRNA expression profiling in prostate cancer. Cancer Res. 2007;67(13):6130-6135.

31. Song H, Liu Y, Pan J, Zhao ST. Expression profile analysis reveals putative prostate cancer-related microRNAs. Genet Mol Res. 2013; 12(4):4934-4943.

32. Ren Q, Liang J, Wei J, et al. Epithelial and stromal expression of miRNAs during prostate cancer progression. Am J Transl Res. 2014;6(4): 329-339.

33. Chen ZH, Zhang GL, Li HR, et al. A panel of five circulating microRNAs as potential biomarkers for prostate cancer. Prostate. 2012;72(13): 1443-1452.

34. Kachakova D, Mitkova A, Popov E, et al. Combinations of serum prostate-specific antigen and plasma expression levels of let-7c, miR-30c, miR-141, and miR-375 as potential better diagnostic biomarkers for prostate cancer. DNA Cell Biol. 2015;34(3):189-200.

35. Ling XH, Han ZD, Xia D, et al. MicroRNA-30c serves as an independent biochemical recurrence predictor and potential tumor suppressor for prostate cancer. Mol Biol Rep. 2014;41(5):2779-2788.

36. Hudson RS, Yi M, Esposito D, et al. MicroRNA-106b-25 cluster expression is associated with early disease recurrence and targets caspase-7 and focal adhesion in human prostate cancer. Oncogene. 2013;32(35): 4139-4147.

37. Szczyrba J, Loprich E, Wach S, et al. The microRNA profile of prostate carcinoma obtained by deep sequencing. Mol Cancer Res. 2010; 8(4):529-538.

38. Poliseno L, Salmena L, Riccardi L, et al. Identification of the miR106b 25 microRNA cluster as a proto-oncogenic PTEN-targeting intron that cooperates with its host gene MCM7 in transformation. Sci Signal. 2010;3(117):ra29.

39. Ambs S, Prueitt RL, Yi M, et al. Genomic profiling of microRNA and messenger RNA reveals deregulated microRNA expression in prostate cancer. Cancer Res. 2008;68(15):6162-6170.

40. Martens-Uzunova ES, Jalava SE, Dits NF, et al. Diagnostic and prognostic signatures from the small non-coding RNA transcriptome in prostate cancer. Oncogene. 2012;31(8):978-991.

41. Zoni E, van der Horst G, van de Merbel AF, et al. miR-25 modulates invasiveness and dissemination of human prostate cancer cells via regulation of $\alpha \mathrm{v}$ - and $\alpha 6$-integrin expression. Cancer Res. 2015;75(11): 2326-2336.

42. Lin $\mathrm{Y}, \mathrm{Chen} \mathrm{H}, \mathrm{Hu} \mathrm{Z}$, et al. miR-26a inhibits proliferation and motility in bladder cancer by targeting HMGA1. FEBS Lett. 2013;587(15): $2467-2473$.

43. Zhou H, Guo W, Zhao Y, et al. MicroRNA-26a acts as a tumor suppressor inhibiting gallbladder cancer cell proliferation by directly targeting HMGA2. Int J Oncol. 2014;44(6):2050-2058.

44. Deng M, Tang HL, Lu XH, et al. MiR-26a suppresses tumor growth and metastasis by targeting FGF9 in gastric cancer. PLoS One. 2013;8(8):e72662.

45. Lv M, Zhang X, Li M, et al. MiR-26a and its target CKS2 modulate cell growth and tumorigenesis of papillary thyroid carcinoma. PLoS One. 2013;8(7):e67591.

46. Wen L, Cheng F, Zhou Y, Yin C. MiR-26a enhances the sensitivity of gastric cancer cells to cisplatin by targeting NRAS and E2F2. Saudi J Gastroenterol. 2015;21(5):313-319.

47. Zhao S, Ye X, Xiao L, et al. MiR-26a inhibits prostate cancer progression by repression of Wnt5a. Tumour Biol. 2014;35(10):9725-9733.

48. Xia M, Duan ML, Tong JH, Xu JG. MiR-26b suppresses tumor cell proliferation, migration and invasion by directly targeting COX-2 in lung cancer. Eur Rev Med Pharmacol Sci. 2015;19(24): $4728-4737$.

49. Wu N, Zhao X, Liu M, et al. Role of microRNA-26b in glioma development and its mediated regulation on EphA2. PLoS One. 2011; 6(1):e16264. 
50. Shen G, Lin Y, Yang X, Zhang J, Xu Z, Jia H. MicroRNA-26b inhibits epithelial-mesenchymal transition in hepatocellular carcinoma by targeting USP9X. BMC Cancer. 2014;14:393.

51. Li D, Wei Y, Wang D, Gao H, Liu K. MicroRNA-26b suppresses the metastasis of non-small cell lung cancer by targeting MIEN1 via NF-кB/MMP-9/VEGF pathways. Biochem Biophys Res Commun. 2016; 472(3):465-470.

52. John Clotaire DZ, Zhang B, Wei N, et al. miR-26b inhibits autophagy by targeting ULK2 in prostate cancer cells. Biochem Biophys Res Commun. 2016;472(1):194-200.

53. Kato M, Goto Y, Matsushita R, et al. MicroRNA-26a/b directly regulate La-related protein 1 and inhibit cancer cell invasion in prostate cancer. Int J Oncol. 2015;47(2):710-718.

54. Koh CM, Iwata T, Zheng Q, Bethel C, Yegnasubramanian S, De Marzo AM. Myc enforces overexpression of EZH2 in early prostatic neoplasia via transcriptional and post-transcriptional mechanisms. Oncotarget. 2011;2(9):669-683.

55. Carlsson J, Davidsson S, Helenius G, et al. A miRNA expression signature that separates between normal and malignant prostate tissues. Cancer Cell Int. 2011;11(1):14.

56. Erdmann K, Kaulke K, Thomae C, et al. Elevated expression of prostate cancer-associated genes is linked to down-regulation of microRNAs. BMC Cancer. 2014; 14:82.

57. Volinia S, Calin GA, Liu CG, et al. A microRNA expression signature of human solid tumors defines cancer gene targets. Proc Natl Acad Sci US A. 2006;103(7):2257-2261.

58. Cao P, Deng Z, Wan M, et al. MicroRNA-101 negatively regulates Ezh2 and its expression is modulated by androgen receptor and HIF-1alpha/ HIF-1beta. Mol Cancer. 2010;9:108.
59. Dang X, Ma A, Yang L, et al. MicroRNA-26a regulates tumorigenic properties of EZH2 in human lung carcinoma cells. Cancer Genet. 2012;205(3):113-123.

60. Varambally S, Cao Q, Mani RS, et al. Genomic loss of microRNA-101 leads to overexpression of histone methyltransferase EZH2 in cancer. Science. 2008;322(5908):1695-1699.

61. Mihelich BL, Maranville JC, Nolley R, Peehl DM, Nonn L. Elevated serum microRNA levels associate with absence of high-grade prostate cancer in a retrospective cohort. PLoS One. 2015;10(4):e0124245.

62. Chhabra R, Dubey R, Saini N. Cooperative and individualistic functions of the microRNAs in the miR-23a $\sim 27 \mathrm{a} \sim 24-2$ cluster and its implication in human diseases. Mol Cancer. 2010;9:232.

63. Ell B, Qiu Q, Wei Y, et al. The microRNA-23b/27b/24 cluster promotes breast cancer lung metastasis by targeting metastasis-suppressive gene prosaposin. J Biol Chem. 2014;289(32):21888-21895.

64. Ishteiwy RA, Ward TM, Dykxhoorn DM, Burnstein KL. The microRNA-23b/-27b cluster suppresses the metastatic phenotype of castration-resistant prostate cancer cells. PLoS One. 2012;7(12):e52106.

65. Goto Y, Kojima S, Nishikawa R, et al. The microRNA-23b/27b/24-1 cluster is a disease progression marker and tumor suppressor in prostate cancer. Oncotarget. 2014;5(17):7748-7759.

66. Wang L, Li B, Lei L, Wang T. MicroRNA-497 suppresses proliferation and induces apoptosis in prostate cancer cells. Asian Pac J Cancer Prev. 2013;14(6):3499-3502.
OncoTargets and Therapy

\section{Publish your work in this journal}

OncoTargets and Therapy is an international, peer-reviewed, open access journal focusing on the pathological basis of all cancers, potential targets for therapy and treatment protocols employed to improve the management of cancer patients. The journal also focuses on the impact of management programs and new therapeutic agents and protocols on

\section{Dovepress}

patient perspectives such as quality of life, adherence and satisfaction. The manuscript management system is completely online and includes a very quick and fair peer-review system, which is all easy to use. Visit http://www.dovepress.com/testimonials.php to read real quotes from published authors. 